\title{
Normalization process of cardiac operations in COVID-19 pandemic
}

\author{
Orhan Gökalp [1]
}

Department of Cardiovascular Surgery, Izmir Katip Çelebi University, Faculty of Medicine, Izmir, Turkey

Received: May 09, 2020 Accepted: May 11, 2020 Published online: May 18, 2020

The severe acute respiratory syndromecoronavirus-2 (SARS-CoV-2; COVID-19), which was first identified in Wuhan province of China in the late December 2019, has infected approximately $3,700,000$ individuals worldwide and more than 250,000 deaths have been reported until the first quarter of May 2020. ${ }^{[1]}$ The level of danger for the modern world's healthcare system is revealed, when the possibility of undiagnosed cases, multiple times more than reported numbers, is considered. As a result of this catastrophic scenario, healthcare systems have been reorganized all over the world. The most widely adopted practice is to prioritize COVID-19 patients in all healthcare units and to postpone all diagnose and treatment procedures to a reasonable future date, unless it is urgent or indispensable. The effect of delay in diagnosis and treatment on patients other that those with COVID-19 is a totally different subject of debate on this kind of practice. Nevertheless, we can briefly state that the whole world has to face with this effect of the temporary, but the de novo healthcare system.

Among diseases with postponed diagnosis and treatment due to COVID-19 pandemic, cardiovascular diseases are among the most risky conditions to delay. As a matter of fact, cardiovascular surgery clinics all over the world are in an attempt to create a strategy from the very beginning of the pandemic. Some countries have published guidelines one after another, when the others have developed algorithms for this subject. ${ }^{[2-4]}$ A commonly used method is prioritizing and ranking the patients and making patient-based plans. ${ }^{[5,6]}$ In this case, potential problems should be handled during this ranking process. For instance, a patient with coronary artery lesions may have a severe ischemic attack or die while waiting after the decision to delay the operation. As another example, there is no guarantee of a $4.8-\mathrm{cm}$-abdominal aortic aneurysm not to rupture during the follow-up period, for sure. That is why maximum attention should be paid in determination of priorities. Another strategy in the process of delaying diagnosis and treatment of cardiovascular diseases is to stay in touch with patients via telecommunication tools or face-to-face. ${ }^{[2-6]}$ Moreover, to be proactive during these follow-ups (e.g. to perform an earlier operation for progressive symptoms) may minimize the potential problems caused by this delaying process.

Surely, urgent operations are being performed during this delaying process. Organization of educated healthcare personnel is critical in this point, as cardiovascular surgery is a discipline with lots of technical team and equipment to be used, compared to other surgical specialties. Management of daily working schedule is very difficult, as this team also provides more or less healthcare services, as well. On the other hand, despite using personal protective equipment, there is a risk of infecting the rest of the team or patients, if there is an asymptomatic team member. As a unit with a large number of personnel, cardiovascular surgery operating teams may be insufficient to provide required social distance. Nonetheless, urgent operations will continue to be performed with protective cautions and all these risks to be considered.

How can normalization be practiced in this period? More importantly, when can normalization be started? A vaccine or a mutation to lower the virulence of the virus is required to stop this pandemic and, as we have none of them at the moment, it is obvious

Corresponding author: Orhan Gökalp, MD. İzmir Katip Çelebi Üniversitesi Tıp Fakültesi Kalp ve Damar Cerrahisi Anabilim Dalı, 35620 Çiğgli, İzmir, Türkiye. Tel: +90 505 - 2168813 e-mail: gokalporhan@yahoo.com

Citation:
Gökalp 0. Normalization process of cardiac operations in COVID-19 pandemic.
Cardiovasc Surg Int 2020;7(1):1-2.

of cardiac operations in COVID-19 pandemic. Cardiovasc Surg Int 2020;7(1):1-2 
that normalization will get started without these items. Undoubtedly, local and universal COVID-19 numbers should be taken into consideration in decision of when to start normalization process. The most serious guideline is from the Canadian Cardiovascular Society, when publications from the beginning of the pandemic are studied. ${ }^{[2]}$ According to this guideline, normalization for cardiovascular operations should be held in three phases. In the first phase, a 0 to $25 \%$-increase in capacity and urgent/emergent cases should be focused on and, when it comes to prioritized out-of-hospital patients, it recommends to select patients who are less likely to require prolonged intensive care unit and hospital length of stay. In the second phase, 25 to $50 \%$ increase in capacity and to maintain in-patient urgent/emergent services while broadening the inclusion of appropriately prioritized out-of-hospital patients are recommended. Examples of these prioritized patients are the ones with severe symptomatic aortic stenosis, left main coronary artery disease, a cardiac tumor with high-risk features for obstruction or embolism, and aortic aneurysm disease with high-risk features such as rapid growth. In the last phase, it recommends a start to return to normal outpatient services. While practicing these recommendations, it should be kept in mind that there may be fluctuations in pandemics and this process should be managed in a dynamic manner.

Another important issue is to rule out COVID-19 before the operation for both considering survival of the patient and protection of personnel. The risk of COVID-19 spread from an intubated patient with COVID-19 in the operation room is very high whether he/she has been diagnosed or not. On the other hand, very high mortality ratios have been, unfortunately, reported on elective cases with COVID-19. Even in studies with small cohorts, the mortality was reported as $20 \%$, regardless of the operation type. ${ }^{[7]}$ Considering such outcomes, preoperative polymerase chain reaction (PCR) test may be useful for elective patients. Patients who are symptomatic and have a negative PCR result can be also confirmed by computed tomography for COVID-19. In the light of these data, we use PCR test right before the operation for the prioritized patients, and the operation is performed as soon as it is resulted, as there will be a risk of COVID-19 infection, even one day is lost after the test result.

In conclusion, clinical trials will provide us an insight and shed light into the strategies for both management of urgent/emergent operations, when the virus spread is at the top and normalization process are right or wrong. Irrespective of the results, it should be always remembered that healthcare systems all over the globe, for the first time, provide healthcare, while simultaneously fighting against such a challenging outbreak with widespread transmission.

\section{Declaration of conflicting interests}

The authors declared no conflicts of interest with respect to the authorship and/or publication of this article.

\section{Funding}

The authors received no financial support for the research and/or authorship of this article.

\section{REFERENCES}

1. World Health Organization. Coronavirus disease (COVID19) Pandemic. Available at: https://www.who.int/ emergencies/diseases/novel-coronavirus-2019 [Accessed: May 8, 2020]

2. Hassan A, Arora RC, Lother SA, Adams C, Bouchard D, Cook R, et al. Ramping Up the Delivery of Cardiac Surgery During the COVID-19 Pandemic: A Guidance Statement from the Canadian Society of Cardiac Surgeons. Can J Cardiol 2020:S0828-282X(20)30415-3.

3. Mavioğlu HL, Ünal EU, Aşkın G, Küçüker ŞA, Özatik MA. Perioperative planning for cardiovascular operations in the COVID-19 pandemic. Turk Gogus Kalp Dama 2020;28:236-43.

4. Barros L, Rivetti LA, Furlanetto BH, Teixeira EM, Welikow A. COVID-19: General guidelines for cardiovascular surgeons (standard guidelines - subject to change). Braz J Cardiovasc Surg 2020;35:I-III.

5. Ünal EU, Mavioğlu HL, İscan HZ. Vascular surgery in the COVID-19 pandemic. J Vasc Surg 2020:S07415214(20)31077-6.

6. Bashir M, Moughal S. Cardiovascular Disease and Surgery Amid COVID-19 Pandemic. J Vasc Surg 2020:S07415214(20)31076-4.

7. Lei S, Jiang F, Su W, Chen C, Chen J, Mei W, et al. Clinical characteristics and outcomes of patients undergoing surgeries during the incubation period of COVID-19 infection. EClinicalMedicine 2020:100331. 